\title{
JUVENILE TAKAYASU ARTERITIS AS CAUSE OF RENOVASCULAR HYPERTENSION
}

Rita Marina Soares de Castro Duarte ${ }^{1, \star}$, Caroline Diniz Bezerra ${ }^{1}$, Frederico Lima de Siqueira Dantas ${ }^{1}$, Edson Gonçalves Ferreira Junior ${ }^{1}$, Américo Mota Júnior ${ }^{1}$, Cristal Felipe Pinheiro ${ }^{1}$

1.Universidade Federal do Vale do São Francisco, Petrolina (PE), Brazil.

*Corresponding author: ritinhaww@hotmail.com

\section{BACKGROUND}

Takayasu arteritis (TA) is a large vessels vasculitis, affecting the aorta and its main branches. It predominates in young women, with higher incidence in Asians. Therefore, it is poorly characterized in children, particularly in western countries. Clinical manifestations include constitutional and vascular symptoms. The initial manifestations are more insidious and nonspecific in children, delaying the diagnosis. This case aims to highlight clinical and angiographic aspects of juvenile TA.

\section{CASE REPORT}

R.P.S.S., female, 13 years old. Previously healthy. She was referred from the cardiology outpatient clinic due to a history of arterial hypertension, holocranial headache, nonventilatory dependent chest pain, fatigue and weight loss of $5 \mathrm{~kg}$, for 2 months. Laboratory tests showed normochromic normocytic anemia, creatinine $0.8 \mathrm{mg} / \mathrm{dL}$, ESR $135 \mathrm{~mm} / \mathrm{h}, 24$-hour proteinuria of $1330 \mathrm{mg}$, normal urinalysis, elevated plasma renin activity. Antinuclear antibody, anti-DNAds, anti-Sm were negative. Normal levels of complement. Antineutrophil cytoplasmic antibody (ANCA) was negative. Hepatitis, HIV and VDRL serologies were negative. Tuberculosis skin test was $8 \mathrm{~mm}$. No epidemiology for tuberculosis. On physical examination, she weighed $56 \mathrm{~kg}$, blood pressure (BP) was $160 \times$ $100 \mathrm{mmHg}$ for the four limbs and there was a bruit in the left renal artery topography. Normal pulmonary and cardiac auscultations. Normal echocardiogram. Chest and abdomen computed tomography angiography demonstrated thickening of the abdominal aorta, occluding up to $60 \%$ at the emergence of the renal arteries, proximal stenosis of the superior mesenteric artery and renal arteries (Figs. 1 and 2). Patient filled Ishikawa criteria modified for TA and criteria for children TA of the European League Against Rheumatism. The Indian Takayasu Arteritis Activity Score (ITAS) 2010 was 8, featuring activity disease. Chemoprophylaxis for tuberculosis was started, prednisone $40 \mathrm{mg} /$ day, methotrexate $20 \mathrm{mg} /$ week, acetylsalicylic acid $100 \mathrm{mg} /$ day, folic acid, prophylaxis for corticosteroidinduced osteoporosis and enalapril. In the outpatient follow-up after 2 months, the patient evolved asymptomatic with improvement in proteinuria and normotension, and ITAS 2010 scored 3.

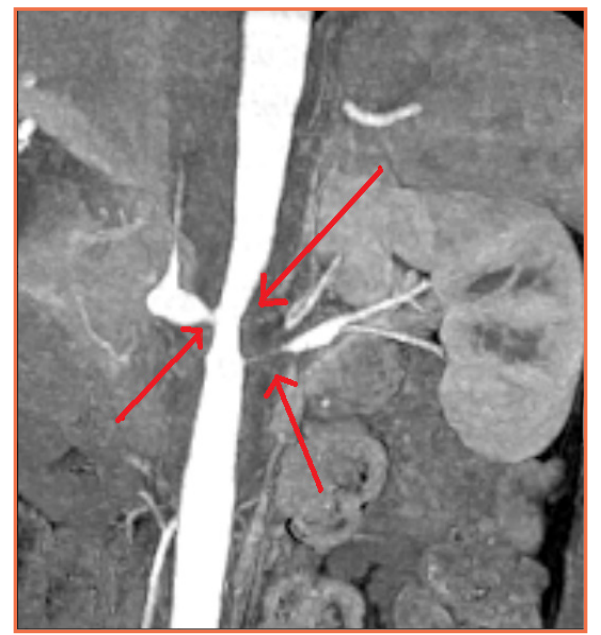

Figure 1. Thickening of the abdominal aorta, at the emergence of the renal arteries and stenosis of the right and left renal arteries. 


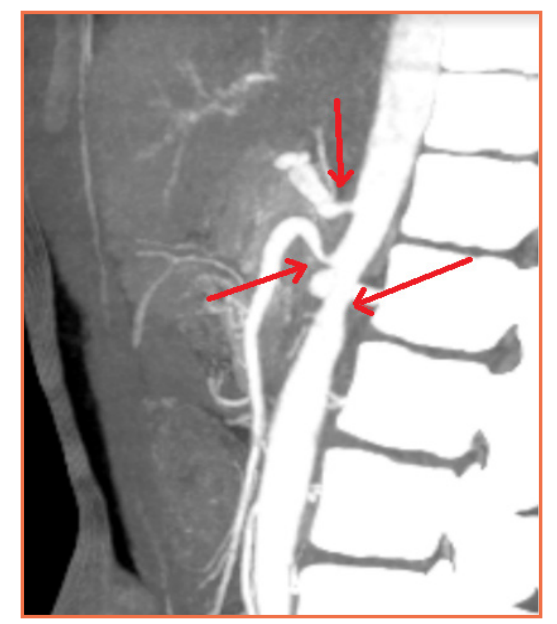

Figure 2. Thickening of abdominal aorta at the level of the celiac trunk with the presence of upper mesenteric artery stenosis.

\section{CONCLUSION}

The involvement of the abdominal aorta and renal arteries is characteristic in juvenile TA, with renovascular hypertension being an alarm signal. In adults, due to the more frequent involvement of the aortic arch, the difference in BP between the limbs is a cardinal sign. In juvenile TA, renal manifestations include nephritic, nephrotic syndrome, hematuria, proteinuria and reduced glomerular filtration rate. Stenosis was the most frequent angiographic change in adults and children. This report highlights the clinical and angiographic differences of juvenile TA, aiming to optimize the recognition of the disease and prevent irreversible vascular damage. 